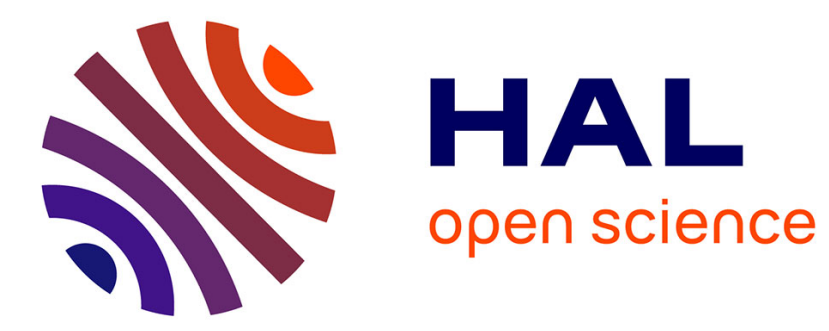

\title{
Design of a bi-harmonic 7-phase PM machine with tooth-concentrated winding
}

\author{
Franck Scuiller, Florent Becker, Hussein Zahr, Eric Semail
}

\section{To cite this version:}

Franck Scuiller, Florent Becker, Hussein Zahr, Eric Semail. Design of a bi-harmonic 7-phase PM machine with tooth-concentrated winding. IEEE Transactions on Energy Conversion, 2020, pp.1-11. 10.1109/tec.2020.2982041 . hal-02524061

\section{HAL Id: hal-02524061 \\ https://hal.science/hal-02524061}

Submitted on 30 Mar 2020

HAL is a multi-disciplinary open access archive for the deposit and dissemination of scientific research documents, whether they are published or not. The documents may come from teaching and research institutions in France or abroad, or from public or private research centers.
L'archive ouverte pluridisciplinaire HAL, est destinée au dépôt et à la diffusion de documents scientifiques de niveau recherche, publiés ou non, émanant des établissements d'enseignement et de recherche français ou étrangers, des laboratoires publics ou privés. 


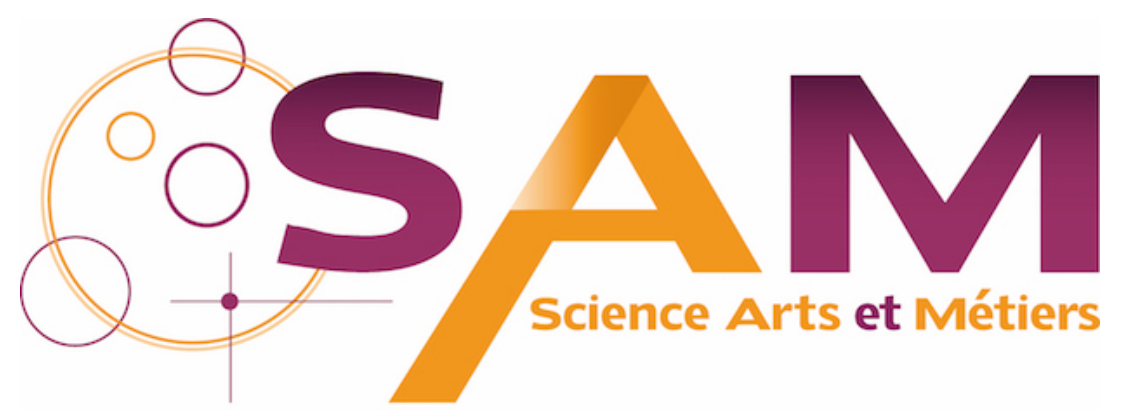

Archive Ouverte - Open Repository

\section{Science Arts \& Métiers (SAM)}

is an open access repository that collects the work of Arts et Métiers ParisTech researchers and makes it freely available over the web where possible.

This is an author-deposited version published in: https://sam.ensam.eu Handle ID: .http://hdl.handle.net/null

\section{To cite this version :}

Franck SCUILLER, Florent BECKER, Hussein ZAHR, Eric SEMAIL - Design of a bi-harmonic 7phase PM machine with tooth-concentrated winding - IEEE Transactions on Energy Conversion p.1-1 - 2020 


\title{
Design of a bi-harmonic 7-phase PM machine with tooth-concentrated winding
}

\author{
Franck Scuiller, Member, IEEE, Florent Becker, Hussein Zahr, Student Member, IEEE, \\ and Eric Semail, Member, IEEE
}

\begin{abstract}
If multi-phase machines equipped with toothconcentrated winding with half a slot per pole and per phase offer interesting characteristics (simplified manufacturing, no space subharmonic, fault-tolerant ability), their low fundamental winding factors make their designs and controls challenging. The paper addresses the case of a seven-phase Surface-mounted Permanent Magnet (SPM) machine which has a fundamental winding factor lower than the third. This so-called bi-harmonic specificity is considered in order to achieve good torque quality (average value and ripples). Regarding the design, the magnet layer is segmented into two identical radially magnetized tiles that cover about three-quarters the pole arc. Regarding the control, the rated Maximum Torque Per Ampere (MTPA) supply strategy (h1h3 control) aims at generating a third harmonic current component greater than the fundamental. A prototype has been manufactured: the ability of the machine to provide smooth torque is experimentally confirmed through the implementation of a simple MTPA control which copes with high distortion in no-load voltage.
\end{abstract}

Index Terms-Multi-phase machine, Surface-mounted Permanent Magnet, Fractional-slot winding, Torque ripple

\section{INTRODUCTION}

Multi-phase motors are widely used in aerospace or marine propulsion applications for reasons such as reliability, smooth torque and distribution of power [1]. For low power propulsion system (less than $10 \mathrm{~kW}$ ), the power partition constraint results from the low DC voltage (less than 60V) that supplies the drive. Hence increasing the phase number enables to limit the rating of the power electronic components. In addition, compactness objective can be more easily achieved if the phase number is considered as a design parameter. For instance, with five-phase machine, third harmonic current injection can be performed to boost the torque [2], [3]. Regarding the rotor, Permanent Magnet (PM) structure contributes to enhance the power density. Furthermore, Surface-mounted Permanent Magnet (SPM) rotor facilitates the ripple torque mitigation that is of critical importance at low speed. If fractional-slot windings contribute to the reduction of cogging torque for SPM machine [4], they also generate magnetomotive force harmonics that could result in excessive magnet losses and stator vibrations. The possible radial stress generated by such fractional-slot winding has also to be evaluated [5]. Machine

F. Scuiller and F. Becker are with the Naval Academy Research Institute, BCRM Brest - EN/GEP CC 600 - 29240 BREST Cedex 9 - FRANCE (e-mail: \{franck.scuiller,florent.becker\}@ecole-navale.fr)

H. Zahr and E. Semail are with Univ. Lille, Arts et Metiers Institute of Technology, Centrale Lille, HEI, L2EP - Laboratoire dElectrotechnique et d'Electronique de Puissance- U LR2697, HESAM Université, F-59000 LILLE, FRANCE (e-mail: \{hussein.zahr,eric.semail\}@ensam.eu) with 0.5 slot per phase and per pole $\left(s_{p p}=0.5\right)$ are known to limit these effects [6]. In addition, the slot filling can also be improved with this solution [5] and the reduction of the end-winding size enhances the volume of active conductor. For the rising mass market of machines for electrification of automotive, new constraints for low cost making process, such as tooth-concentrated windings, are imposed. It can be noted that numerous three-phase electrical machines for automotive applications are equipped with tooth-concentrated windings with $s_{p p}=0.5$ : Toyota Prius (12slots/8poles), Honda Civic Accord 2005 (24 slots/16 poles), Hyundai Sonata (24 slots/16 poles) and Bosch IMG300 (36 slots/24 poles). When fault tolerance is required as for steering motors (steerby-wire application) or even for automotive traction with a single electrical motor, more than three phases are necessary. Therefore, multi-phase tooth-concentrated windings are often considered as the right option when fault tolerant abilities are wanted [7].

However, if the phase number is higher than 3, the toothconcentrated windings with 0.5 slot per phase and per pole present unusual properties in so far as the fundamental winding factor is lower than the third one. Subsequently, this kind of winding is usually disregarded at the design step. Actually machines equipped with this particular windings should operate with a rotating field that contains at least two space harmonics of the same order. Then an acceptable level of torque could be obtained and, to some extent, these machines could be qualified as bi-harmonic or double-polarity one. For 5-phase machine, the possible advantages of this bi-harmonic configuration regarding the torque ripple, the losses limitation and the speed range enlargement are discussed in [8], [9] for the Surface-mounted PM version and in [10], [11] for the Interior PM version. Referring to the 3-phase counterpart (with 0.5 slot per pole and per phase), the five-phase version always keeps the inherent advantage of the fault tolerant ability.

The present paper investigates the 7-phase SPM machine version. The main motivation is to show the feasibility of this machine that, due to high degrees of freedom for the control, can achieve acceptable torque density, low torque ripple and also high fault tolerant ability. According to the preliminary design reported in [12], for the aforementioned criteria, good performances could be expected if the rotor pole consists in two identical radially magnetized magnets that span about three-quarters of the pole arc. Basically, referring to [12], this paper provides the experimental results obtained with the manufactured prototype. For the 7-phase machine, the used control scheme is the one theoretically justified in 
[13], [14], experimentally applied to an induction machine in [15] and to a double-rotor axial flux SPM machine in [16]. For the latter, it should be noted that the 7-phase axial-flux machine exhibits a no-load voltage with only one significant harmonic, the third whose magnitude only represents $20 \%$ of the fundamental, thus contrasting with the bi-harmonic 7-phase machine here analyzed. Therefore, one of the objectives of the present paper is to experimentally prove that, with multi-phase SPM machines, even if the no-load voltage exhibits a high distortion rate, a good torque quality can be attained with a quite simple and easy-to-implement control.

The first part introduces the multi-machine decomposition for seven-phase SPM machine in order to highlight the degrees of freedom in terms of controls and to determine the possible Maximum-Torque-Per-Ampere (MTPA) control strategies for the bi-harmonic 7-phase machine. From the rated MTPA supply that consists in injecting first and third harmonics of current, the second part reminds the fundamentals of the machine design [12] and provides the numerical simulations used to validate the design. The last part reports the experimental results from the test bench with real-time control.

\section{7-PHASE SPM MACHINE MODELING FOR CONTROL}

\section{A. Multi-machine decomposition}

The multi-machine decomposition of a 7-phase SPM machine is detailed in [16]. To establish this modeling, the magnetic behaviour of the multi-phase machine is described with linear applications, thus meaning that the magnetic saturation and the demagnetization issue are not considered (this is usually verified with SPM machines due to their large air gap). With these hypotheses, it can be shown that a starconnected seven-phase SPM machine behaves as three twophase virtual machines that are magnetically independent but electrically and mechanically coupled [17]. Furthermore, since the rotor saliency can be neglected with SPM machines, the electrical harmonics are distributed among the three virtual machines: the virtual machine sensitive to the fundamental is called h1-machine whereas the two others sensitive to the third harmonic and the fifth harmonic are called h3-machine and h5machine respectively. The harmonic distribution (restricted to odd orders) yields:

- $1^{\text {st }}, 13^{\text {th }},(14 k \pm 1)^{\text {th }}$ harmonics belong to h1-machine

- $3^{r d}, 11^{t h},(14 k \pm 3)^{t h}$ harmonics belong to h3-machine

- $5^{r d}, 9^{t h},(14 k \pm 5)^{t h}$ harmonics belong to h5-machine.

Actually the virtual machine is a physical reading of the mathematical subspace built on the linear application that describes the phase-to-phase magnetic couplings. By using generalized Concordia transform [16], a two-dimension subspace is usually represented with $\alpha \beta$-axis circuit in a stationary frame $\left(\left\{\alpha_{1}, \beta_{1}\right\},\left\{\alpha_{3}, \beta_{3}\right\}\right.$ and $\left\{\alpha_{5}, \beta_{5}\right\}$ for h1, h3 and h5 machines respectively) or with $d q$-axis circuit in a rotating frame $\left(\left\{d_{1}, q_{1}\right\},\left\{d_{3}, q_{3}\right\}\right.$ and $\left\{d_{5}, q_{5}\right\}$ for $\mathrm{h} 1, \mathrm{~h} 3$ and $\mathrm{h} 5$ machines respectively). The three virtual machines are also characterized by their cyclic inductances $\left(L_{1}, L_{3}\right.$ and $\left.L_{5}\right)$. This decomposition is illustrated by Fig.1.

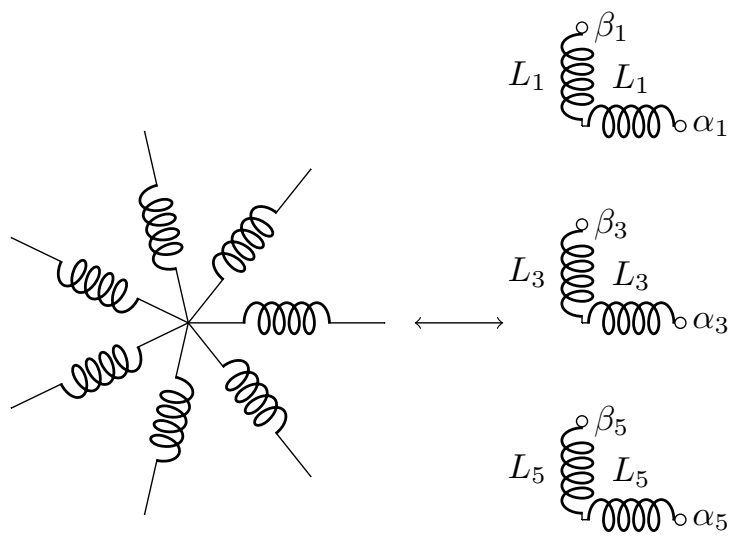

Fig. 1. Decomposition of a 7-phase machine into three 2-phase machines

The electromagnetic torque $T$ is the sum of the three elementary torques produced by $\mathrm{h} 1, \mathrm{~h} 3$ and $\mathrm{h} 5$ virtual machines (denoted $T_{1}, T_{3}$ and $T_{5}$ ):

$$
T=T_{1}+T_{3}+T_{5}
$$

With a voltage source inverter, a simple and efficient control, so-called multi-machine control, can be implemented [14]: it consists in supplying the 7-phase machine with currents that contain only the first, the third and the fifth harmonics. More specifically, this means that these three current harmonics should be regulated. This operation is facilitated if the cyclic inductances $\left(L_{1}, L_{3}\right.$ and $\left.L_{5}\right)$ are of the same order [18], this property being obtained with tooth-concentrated winding.

\section{B. Pulsating torque analysis}

For multi-phase machine, the origins of the pulsating torque (ripple torque of the electromagnetic torque) can be precisely determined with the multi-machine decomposition. Basically, the electromagnetic torque is the sum of the phase to phase products of the elementary back-emfs $\epsilon_{n}$ (defined as the backemfs at one rad/s speed) with the phase currents $i_{n}$ ( $\gamma$ being the electrical angle):

$$
T(\gamma)=\sum_{n=0}^{N-1} \epsilon_{n}(\gamma) i_{n}(\gamma)
$$

In (2), $N$ is the phase number $(N=7)$. The phase $n$ elementary back-emf can be expanded into Fourier series. If $E_{h}$ is the RMS value of the h-order harmonic term of the elementary back-emf, the following relation can be written:

$$
\epsilon_{n}(\gamma)=\sum_{h=1}^{+\infty} E_{h} \sqrt{2} \sin \left(h \gamma-h n \frac{2 \pi}{N}\right)
$$

The same operation can be done for the phase current. The following relation is obtained where $I_{g}$ and $\theta_{g}$ respectively denote the g-th harmonic RMS value and the g-th harmonic phase angle of the current:

$$
i_{n}(\gamma)=\sum_{g=1}^{+\infty} I_{g} \sqrt{2} \sin \left(g \gamma-g n \frac{2 \pi}{N}-\theta_{g}\right)
$$


Under multi-machine control, the torque $T_{k}$ produced by virtual machine indexed $k$ ( $k$ equal 1,3 or 5 ) results from the interaction of the k-th harmonic of the current with the set of particular back-emf harmonics predicted by the multimachine decomposition (see subsection II-A). By using relations (2), (3) and (4), by considering that the back-emf contains only odd order harmonics, the electromagnetic torque $T_{k}$ can be expressed as follows:

$$
\begin{aligned}
T_{k}(\gamma) & =N E_{k} I_{k} \cos \theta_{k} \\
& +N \sum_{c=1}^{+\infty}-E_{14 c-k} I_{k} \cos \left(14 c \gamma-\theta_{k}\right) \\
& +N \sum_{c=1}^{+\infty} E_{14 c+k} I_{k} \cos \left(14 c \gamma+\theta_{k}\right)
\end{aligned}
$$

Relation (5) shows that the pulsating torque frequencies are multiple of 14 times the electrical frequency. This result is confirmed in [19] that provides theoretical developments concerning the torque ripples of multi-phase machine supplied with several current harmonics. Relation (5) also quantifies the magnetic independence of the virtual machines regarding the pulsating torque generation: the 1st, 3rd and 5th harmonics of current do no interact each other to generate pulsating torque. Therefore, if the virtual machines are sinewave (i.e. if the back-emf contains only the first, the third and the fifth harmonic), the electromagnetic torque will be constant under multi-machine control. It can be considered that this property is quite easily obtained for h1-machine and h3-machine since the air gap flux leakage increases with the harmonic order (i.e. the 13th and 11th back-emf harmonic are naturally low referring to the 1st and 3rd ones). Finally, even if the back-emf exhibits a high distortion rate, a sinus control of the virtual machine currents may result in low torque ripple.

\section{Multi-phase MTPA control strategy}

For a SPM machine, Maximum Torque Per Ampere (MTPA) is achieved by generating a current waveform similar to the back-emf waveform [20]. For a 7-phase machine, this MTPA supply can be simply implemented by only accounting harmonics 1, 3 and 5 of the back-emf (as described in [21] for 5-phase SPM machine). Subsequently, the phase $n$ current reference should be aligned with the elementary back-emf, thus meaning that current-to-back-emf angle $\theta_{k}$ defined in (4) should be canceled for each virtual machine. The reference currents can be expressed as follows:

$$
i_{n}(\theta)=\sum_{h \in\{1,3,5\}} I_{h} \sqrt{2} \sin \left(h \theta+h n \frac{2 \pi}{7}\right)
$$

According to (6), for the three virtual machines, the reference currents are sinus if projected into the stationary frames $\left(\left\{\alpha_{1}, \beta_{1}\right\},\left\{\alpha_{3}, \beta_{3}\right\}\right.$ and $\left.\left\{\alpha_{5}, \beta_{5}\right\}\right)$ and constant if projected into the rotating frames $\left(\left\{d_{1}, q_{1}\right\},\left\{d_{3}, q_{3}\right\}\right.$ and $\left.\left\{d_{5}, q_{5}\right\}\right)$. As current-to-back-emf angles are canceled, $d_{1}$-axis, $d_{3}$-axis and $d_{5}$-axis current references are zero. $q_{1}$-axis, $q_{3}$-axis and $q_{5^{-}}$ axis current references are calculated according to the wanted virtual machines torque distribution.
With multi-phase machines, several MTPA control strategies can be achieved according to the number of virtual machines used to produce the torque. For instance, with star-connected 3-phase machine represented by a single virtual machine, only one MTPA control is possible. By contrast, with a star-connected 5-phase machine characterized by two virtual machine (h1 and h3), the degrees of freedom are increased. For instance, in [11], three MTPA controls are investigated (h1, h3 and h1h3). For the 7-phase machine under consideration, the different MTPA supplies are distinguished with the current ratios $r_{1}, r_{3}$ and $r_{5}$ (defined for a given phase RMS current $\left.I_{b}\right)$ :

$$
\left(r_{1}, r_{3}, r_{5}\right)=\left(\frac{I_{1}}{I_{b}}, \frac{I_{3}}{I_{b}}, \frac{I_{5}}{I_{b}}\right)
$$

According to the number of virtual machine chosen to produce torque, the ratios $r_{1}, r_{3}$ and $r_{5}$ are determined by considering the values of the elementary back-emf harmonics. A biharmonic machine is characterized by back-emf fundamentals and third harmonics of the same order, thus increasing the degrees of freedom for the control. Table I lists the four possible control strategies for the 7-phase bi-harmonic machine: h1, h3, h1h3 and h1h3h5 controls. h1 and h3 correspond to sinus control for h1 and h3 machine while h1h3 aims at generating the torque with the two largest back-emf harmonics. Hence the machine should be designed for this control. h1h3h5 can be considered as fifth harmonic current injection: a torque enhancement (higher average value and/or lower ripples) can be obtained according to the amplitude of the fifth harmonic of the back-emf.

TABLE I

CURRENT REPARTITION FOR THE FOUR POSSIBLE CONTROLS

\begin{tabular}{c|ccc} 
Control & $r_{1}$ & $r_{3}$ & $r_{5}$ \\
\hline h1 & 1 & 0 & 0 \\
h3 & 0 & 1 & 0 \\
h1h3 (rated) & $\frac{E_{1}}{\sqrt{E_{1}^{2}+E_{3}^{2}}}$ & $\frac{E_{3}}{\sqrt{E_{1}^{2}+E_{3}^{2}}}$ & 0 \\
h1h3h5 & $\frac{E_{1}}{\sqrt{E_{1}^{2}+E_{3}^{2}+E_{5}^{2}}}$ & $\frac{E_{3}}{\sqrt{E_{1}^{2}+E_{3}^{2}+E_{5}^{2}}}$ & $\frac{E_{5}}{\sqrt{E_{1}^{2}+E_{3}^{2}+E_{5}^{2}}}$
\end{tabular}

\section{MACHINE DESIGN}

\section{A. Design specifications}

The 7-phase machine here considered is equipped with a tooth-concentrated fractional-slot winding with a number of slots per pole and per phase $s_{p p}=0.5$. The resulting winding factors are $k_{w, 1}=0.43, k_{w, 3}=0.97$ and $k_{w, 5}=0.78$. These values require to design a rotor that generates at least two significant harmonic components, the first and the third. Therefore an acceptable torque production capability can be expected despite the low fundamental winding factor. On the control side, h1 and h3 machines have to be current regulated. Subsequently, for the rating control strategy (h1h3 control in Table I), the 7-phase machine is designed with assuming that only h1 and h3 machines contribute to the torque, thus meaning that h5 machine current references are zero. 


\section{B. Specific magnet layer segmentation}

The base idea consists in designing a rotor that generates a suitable level of first and third back-emf harmonics. The constraint is to obtain low torque ripple when $\mathrm{h} 1 \mathrm{~h} 3$ control (see Table I) is applied. A particular attention is drawn to the cogging torque that can be very large for this kind of SPM machine. Magnet segmentation is a solution to mitigate the cogging torque [22]. Consequently, solutions where the rotor consists in several identical radially magnetized tiles, regularly space shifted, are explored. By using an analytical 2D field computation model [23], keeping constant the magnetic circuit (stator and rotor core, slot geometry, air gap...) and magnet height, several machine designs that only differ from the number of magnets per pole $n_{a}$ are evaluated. Each design is characterized by the magnet arc cover ratio, denoted $\tau_{m}$ : this quantity is the sum of the magnet angular arc divided by the pole angle. For instance, if magnets cover the full pole arc, the magnet arc cover ratio is one. Magnet arc cover ratio facilitates the comparison of machines with different number of magnets per pole: a given magnet arc cover ratio corresponds to a given magnet volume whatever the number of magnets per pole is. The choice of the number of magnets per pole and the cover ratio should be a compromise between good value of average torque and torque ripple reduction.

TABLE II

PARAMETERS FOR THE 7-PHASE MACHINE (2KW AT 1000RPM)

\begin{tabular}{cc}
\hline Parameter & Value \\
\hline Pole/Slot numbers & $4 / 14$ \\
Stator diameter $(\mathrm{mm})$ & 88 \\
Air gap length $(\mathrm{mm})$ & 1 \\
Magnet layer thickness & 3 \\
Rotor yoke thickness $(\mathrm{mm})$ & 17.3 \\
Slot depth $(\mathrm{mm})$ & 38.3 \\
Stator yoke thickness $(\mathrm{mm})$ & 17.3 \\
Effective length (mm) & 140 \\
Slot number & 14 \\
Slot width to slot pitch & 0.5 \\
Slot-opening to slot width & 0.5 \\
Slot-closing thickness (mm) & 2
\end{tabular}

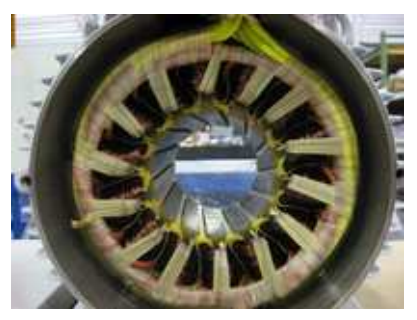

(a) Stator winding

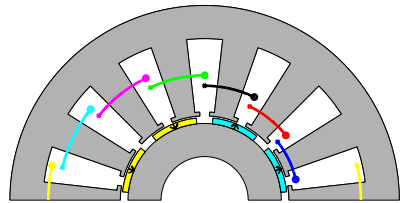

(b) Magnetic circuit $\left(n_{a}=2\right.$ and $\left.\tau_{m}=0.74\right)$
Fig. 2. 7-phase SPM machine with tooth-concentrated winding

Table II lists the main parameters of the 4-pole 7-phase machine (that was imposed during the exploration of the magnet layer) and Fig.2a is a picture of the stator with the manufactured tooth-concentrated winding. Fig.2b illustrates the electromagnetic circuit for a design with two magnets per pole $\left(n_{a}=2\right)$ and a magnet arc cover ratio equal to 0.74 $\left(\tau_{m}=0.74\right)$. According to $2 \mathrm{D}$ analytical field computation
[23], this solution is the best found compromise in [12]. On the one hand, the pole segmentation into two magnets $\left(n_{a}=2\right)$ brings the higher average torques referring to solutions without segmentation $\left(n_{a}=1\right)$ or higher segmentations $\left(n_{a}>2\right)$. On the other hand, the magnet arc cover ratio $\tau_{m}$ of about three-quarters results in low cogging torque and low torque ripple level (TRL, max-to-min torque to average torque). In particular, Fig. 3 reports the electromagnetic TRL for the four possible controls according to the magnet arc cover ratio. A magnet arc cover ratio of about 0.74 is finally selected: with this value, low electromagnetic TRL are expected whatever the control is.

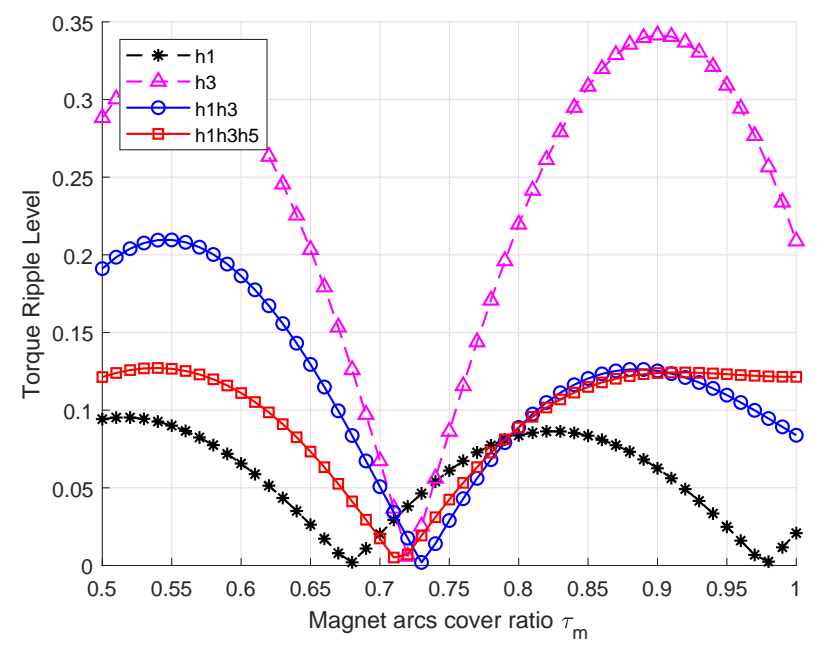

Fig. 3. Electromagnetic TRL according to the possible controls

Bearing in mind that the effective torque ripple reduction will depend on the model accuracy, the manufacturing precision and the controller performances, a slight stator skew angle is finally specified. Without particular magnet segmentation, the cogging torque fundamental frequency is 28 times the mechanical speed. In this case, the skew angle should equal 12.86deg (360/28). But, as the pole consists in two identical magnets regularly spaced, the fundamental of the cogging torque is theoretically eliminated. Consequently, chosing a skew angle of $6.43 \mathrm{deg}$ should cancel the secondorder harmonic of the cogging. Finally, for the prototype, these two design arrangements (magnet segmentation and skewing at $6.43 \mathrm{deg}$ ) should result in a very low cogging torque. It should be precised that considering the skew angle when selecting the magnet number and the magnet arc cover ratio would not change the conclusion because the skew harmonic coefficients are quite large for the first and the third electrical harmonics ( 0.998 and 0.981 respectively). The next part aims at validating this design with FEA simulations.

\section{FEA simulation}

The 7-phase machine is analyzed with two-dimensional (2D) finite-elements analysis software FEMM [24]. The simulation considers the non linear B-H curve for the electrical steel (M400-50A). Fig.4 shows the estimated flux lines at noload. The right sizing of the magnetic circuit can be verified: 
the saturation value (about 1.4T) for the flux density is not attained except in some parts of the slot-closing regions.

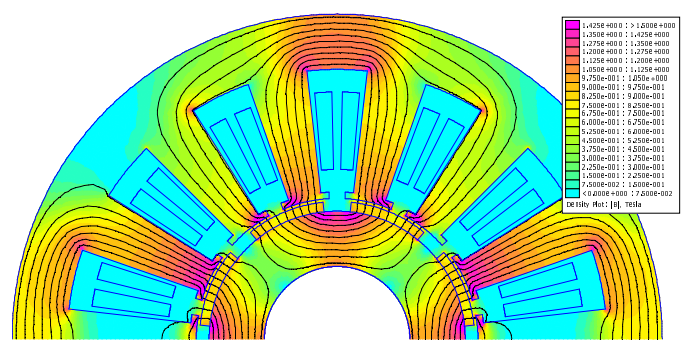

Fig. 4. Flux lines at no-load

Figure 5 reports the analytical and 2D numerical estimations of the phase-to-neutral no-load voltage at 1000rpm speed. For analytical and numerical estimations, the stator skew angle is considered by averaging the flux according to the axial length. A good agreement between the analytical results (used to determine the magnet segmentation in the previous part) and the FEA calculations is observed. The particular harmonic content of the back-emf can be noted: the third harmonic term is about 1.3 times the fundamental, thus highlighting the necessity of generating torque with a current that contains a third harmonic component higher than the fundamental one (this is formulated by the rated h1h3 control). It can noted that the distortion rate of the no-load voltage (defined as signal RMS value to fundamental amplitude) takes the unusual value of about $165 \%$. For the record, a squarewave signal has a distortion rate of $111 \%$.
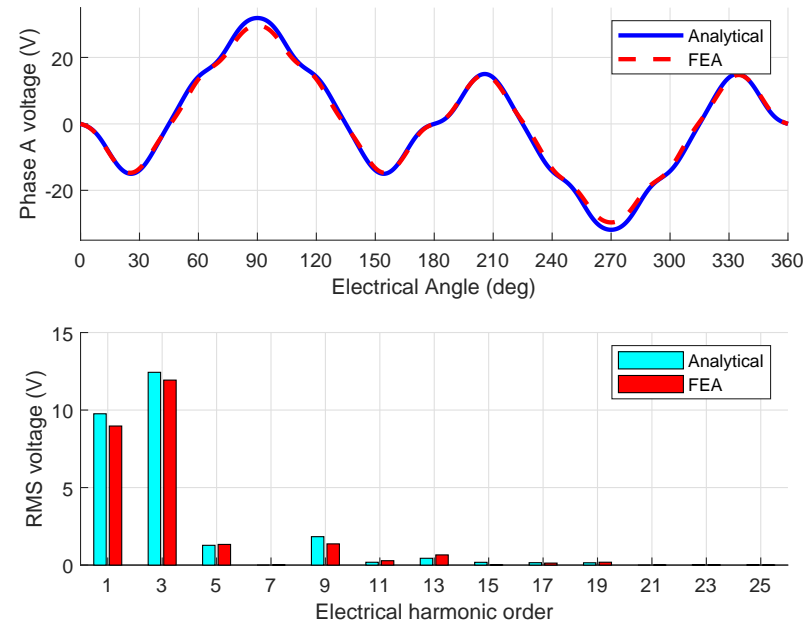

Fig. 5. No-load voltage (back-emf) estimations (at 1000rpm)

Fig.6 reports the analytical and numerical estimations of the cogging torque, but without accounting the skewing: a good agreement is observed. Since the pole is segmented into two identical magnets, the fundamental component of the cogging torque (that corresponds to the space harmonic order 28) is theoretically canceled. The point is confirmed by both analytical and numerical calculations (for the latter, the non-zero value could result from numerical errors). The skew
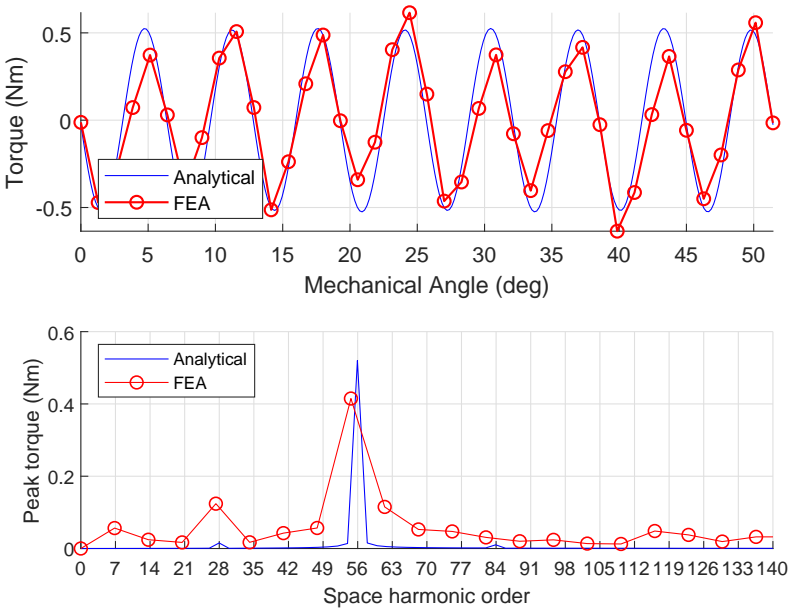

Fig. 6. Analytical and FEA cogging torque estimations (without skewing)

harmonic coefficients for orders 28 and 56 are respectively equal to 0.64 and 0 . A very low cogging torque is then expected for the real machine.

Figure 7 focuses on the numerical estimations of the torques for the different MTPA control strategies $(h 1, h 3, h 1 h 3$ and $h 1 h 3 h 5)$ at the rated RMS current $I_{b}$. For these three simulations, the stator skew effect on the torque waveform is illustrated: each solid line torque plotting is associated to a dash line one that corresponds to the torque without skewing. Therefore, the skewing effect on the mitigation of the torque ripple, mainly due to cogging, can be observed. h1 control is computed in order to demonstrate the necessity of using the rated $\mathrm{h} 1 \mathrm{~h} 3$ control to obtain the nominal torque, with low torque ripple as targeted in the design procedure. Furthermore, in accordance with the multimachine theory, as h3-machine is more sinewave than h1-machine (this is shown by Fig.5 where the 11th harmonic to 3rd harmonic back-emf ratio is lower than the 13th harmonic to 1st harmonic one), the TRL with h3 control is lower than the one with $\mathrm{h} 1$ control. This propery can be quantified with virtual machine torque formulation (5). Figure 7 also shows that the fifth harmonic injection (performed with h1h3h5 control) can slightly enhance the average torque without increasing the ripple. Overall the estimated TRL match the ones presented in Fig. 3 for a magnet cover ratio equal to 0.74 .

\section{EXPERIMENTAL VALIDATION}

A prototype is manufactured according to the previous specifications. Fig.8 show the experimental test bench. The converter consists in IGBT modules (SEMIKRON SKM50GB123D) supplied from a DC power source. The prototype is controlled with a dSpace system (DS1005 control card, DS2004 card for high-resolution analog conversion, DS5101 PWM card with 12 outputs). The hardware implementation on DS1005 card results from the control algorithm computed with Matlab/Simulink, according to the strategy detailed in subsection II-C (the carrier frequency is $12 \mathrm{kHz}$ ). As shown in Fig.8, the 7-phase machine is mechanically loaded by a standard brushless machine (that exhibits very low torque 


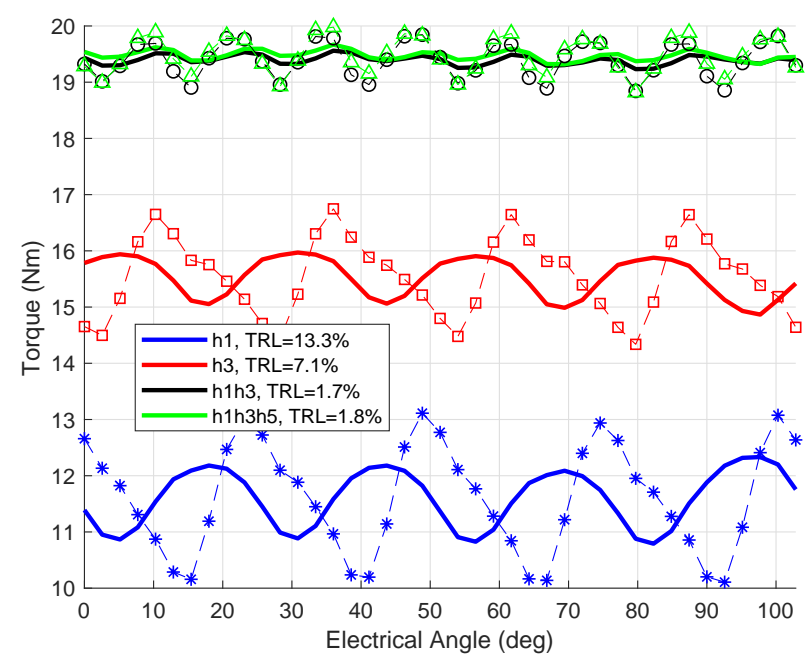

Fig. 7. Full torque according to FEA (dash line: without skewing)

ripples and embeds the position sensor). A torque sensor is located at the shafts connection. For the no-load tests, the brushless machine is supplied with an industrial inverter (that embeds a vector control) whereas, for the load tests, the brushless machine is electrically connected to resistances.

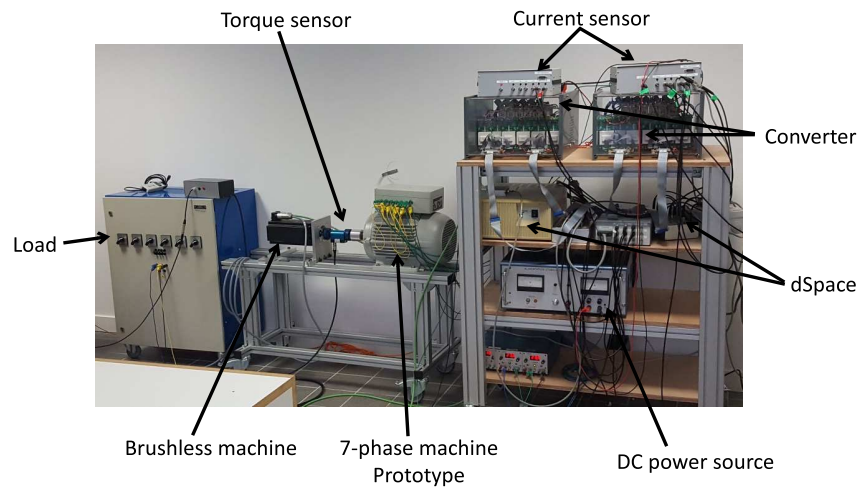

Fig. 8. Test bench overview

\section{A. No-load torque}

The cogging torque amplitude is indirectly estimated by driving the 7-phase machine with the brushless machine at low speed. The torque waveform according to the torque sensor is recorded and analyzed. Fig. 9 reports the results for the test at 20rpm (that corresponds to a mechanical frequency of $0.33 \mathrm{~Hz}$ ). Theoretically, for the 7-phase machine, the cogging torque fundamental frequency is 28 times the mechanical frequency. Subsequently, the Fourier transform of the torque signals reveals two components that directly relate to the cogging torque: the component at $9.33 \mathrm{~Hz}$ (with amplitude of about $0.1 \mathrm{Nm}$ ) is the fundamental whereas the components at $18.67 \mathrm{~Hz}$ (with amplitude of about $0.05 \mathrm{Nm}$ ) is the second order harmonic. Going back to the design objectives (discussed in part III-B), the cogging torque fundamental elimination due to the segmentation of the pole into two magnets is not completely obtained. Consequently, the skew angle (chosen to reduce the second harmonic of the cogging) does not mitigate the cogging torque as much as expected. We think that this deviation results from possible mechanical unbalance and pole dissymetry. This hypothesis could be confirmed by the presence of the frequencies $2.7 \mathrm{~Hz}$ and $5.3 \mathrm{~Hz}$ that correspond to the number of magnets (8) and two times the number of magnets respectively. To conclude, the prototype does not exactly behave as predicted by the design in so far as the cogging torque is not eliminated, because of possible mechanical unbalance and magnet layer dissymmetry (and also manufacturing processes as it will be discussed in the next subsection). Nevertheless, as targeted, the prototype exhibits a quite low cogging torque.
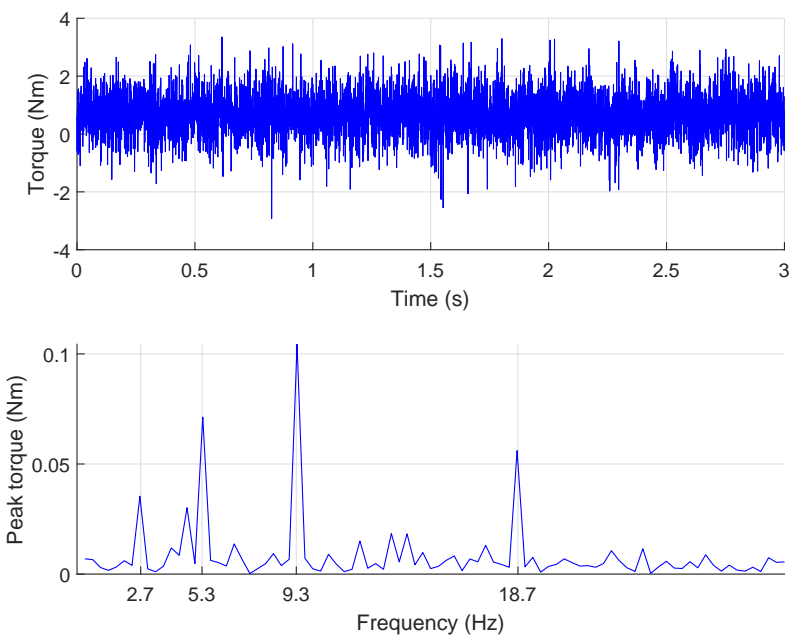

Fig. 9. Measured torque for the 7-phase machine at no load, driven at 20rpm

\section{B. Back-emf}

For this test, the 7-phase machine is in open-circuit and is driven by the brushless machine at 1000rpm. The seven phase-to-neutral voltages (phase back-emfs) are recorded and a Fourier analysis of each voltage signal is done to check the correct balance of the voltages. Fig.10 reports the measured voltages projected into the Concordia base in order to have a clear insight of the double polarity of the machine: due to tooth-concentrated 7-phase winding and the adapted design, the voltage in plane $\left\{\alpha_{3}, \beta_{3}\right\}$ that relates to polarity $3 p(\mathrm{~h} 3)$ is of the same order as the voltage in plane $\left\{\alpha_{1}, \beta_{1}\right\}$ that relates to polarity $p(\mathrm{~h} 1)$. Furthermore, h1 and h3 virtual machines have a sinus back-emf, thus being particularly useful to reduce the pulsating torques (as discussed in part II-B). It should be mentioned that the homopolar voltage (negligible) is not reported in Fig. 10.

Fig.11 focuses on the measured back-emf (phase A) over one electrical period: the waveform and the Fourier series are drawn in order to compare with the values predicted by the design (see Fig.5). The relative amplitudes of harmonics 1,3 and 5 are quite similar: for instance, the harmonic 3 to harmonic 1 ratio is about 1.3 for both experimental and FEA results. Consequently, the back-emf distortion rate $(162 \%)$ is close to the predicted ones $(165 \%)$. Nevertheless, a non-negligible deviation appears for harmonics 9 and 13: 

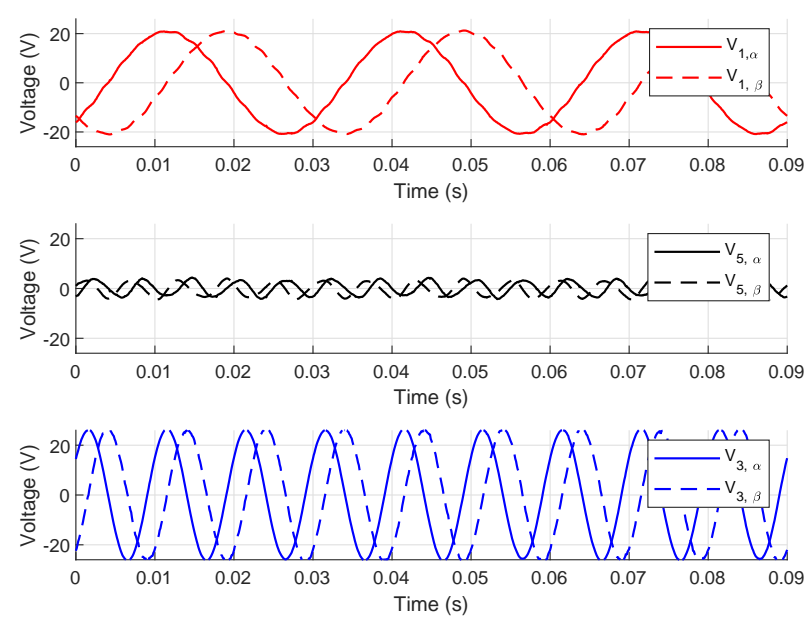

Fig. 10. Measured back-emfs projected into Concordia base (1000rpm)

the measured values are zero which is not in accordance with the numerical predictions. As for the cogging torque, the difference between numerical predictions and experiments may result from geometrical differences, manufacturing uncertainties and manufacturing process. In particular, the stator iron has been laser cut and this process is known to decrease the magnetic performances near the cutting edge [25]. We think that most of the deviation results from this point. For instance, according to FEA simulations, the flux density in the slot-closing area could reach 1.3T at no-load (as visible in Fig.4). This value is lower than the saturation one (for the used M400-50A electrical steel), but the laser cutting could reduce the magnetic saturation by more than $15 \%$, especially for small machines with thin slot-closing regions (as for the prototype here considered). This hypothesis could explain the deviation from numerical results. If this is true, the real machine would operate with quasi-saturated closing-slots area, thus making it magnetically behave as a machine with opened slots. This assumption is verified by computing a FEA simulation with opened slots. The results correspond to the curves labeled "FEA with opened slots" in Fig.11. The matching with experimental results is significantly improved. It should be added that the same verification has been done for the cogging torque: the fundamental component (28th space harmonic) with opened slots is about 3 times higher than the one with semi-closed slots, thus confirming again our hypothesis. Finally, as it can be observed in Fig.10, the prototype owns quasi-sinus backemf for the three virtual machines $\left(\left\{\alpha_{1}, \beta_{1}\right\}\right.$ plane, $\left\{\alpha_{3}, \beta_{3}\right\}$ plane and $\left\{\alpha_{5}, \beta_{5}\right\}$ plane). Subsequently, the actual TRL with the different MTPA controls should be quite similar.

\section{Load tests with MTPA controls}

For these tests, the load resistances (visible in Fig.8) are set so that the machine rotates at about $60 \mathrm{rad} / \mathrm{s}$ (570rpm) for $5.5 \mathrm{Nm}$ reference torque. The currents of the 7-phase machine is controlled to reach the reference torque value $(5.5 \mathrm{Nm})$ for the four possible MTPA controls (h1, h3, h1h3 and h1h3h5).

Fig. 12 reports the measured line currents for h1h3 control. The Fourier series of the current signals reveals a good
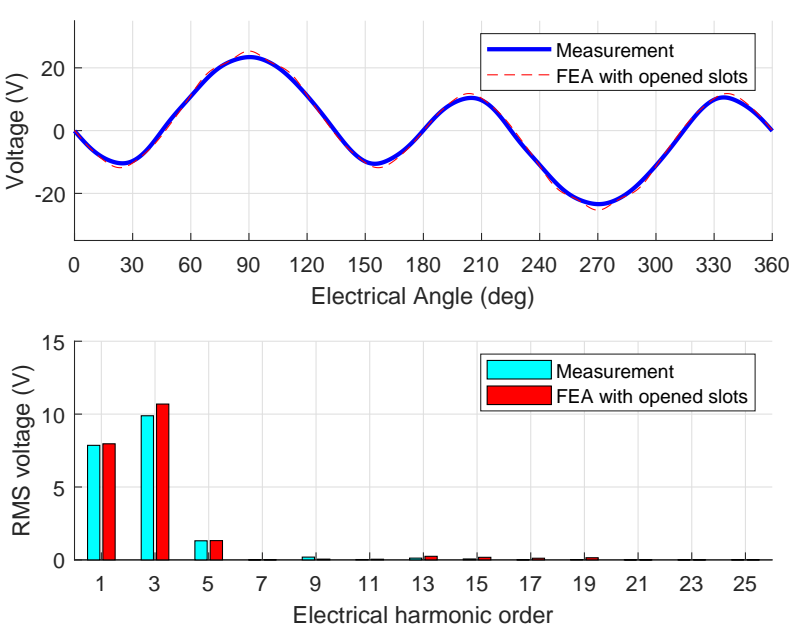

Fig. 11. Measured no-load phase-to-neutral voltage (phase A) at 1000rpm

balance between the currents and illustrate the bi-harmonic characteristic feature of the prototype. Resulting from the same experiments as Fig.12 in h1h3 control, Fig.13 gives the corresponding phase-to-neutral voltages (outputs of the current controllers). In accordance with the current spectrum, the Fourier expansions of the voltage signals shows that the voltages mainly consist of three components: the fundamental and the third harmonic that are the working components and the fifth harmonic that compensates the h5-machine back-emf.
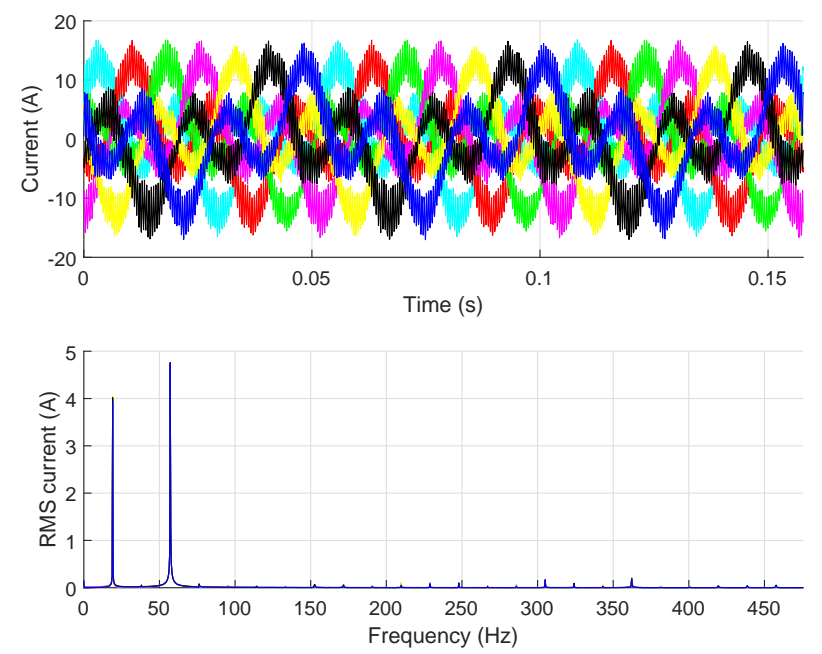

Fig. 12. Phase currents with h1h3 control

Fig.14 reports for each control the measured currents (for phase A). Each subfigure indicates the RMS currents and the peak current. As predicted, the required RMS currents is significantly reduced with $\mathrm{h} 1 \mathrm{~h} 3$ and h1h $3 \mathrm{~h} 5$ controls. Subsequently, the roughly estimated efficiency (electromagnetic power divided by electrical power) is enhanced: about $60 \%$ with h1h3 and h1h3h5 controls versus $50 \%$ with h3 control or $40 \%$ with h1 control (for the record, $5.5 \mathrm{Nm}$ corresponds to about $30 \%$ the rated torque of the prototype). Furthermore, referring to h1 control, a slight decrease of the peak currents is obtained with $\mathrm{h} 3$ and $\mathrm{h} 1 \mathrm{~h} 3$ controls (about $2 \mathrm{~A}$ less) and with 

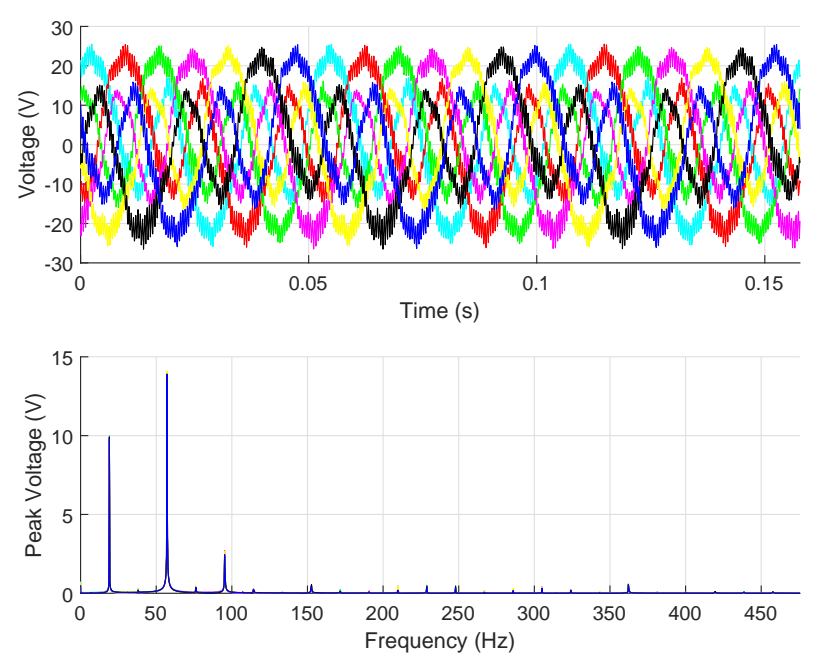

Fig. 13. Phase-to-neutral voltages with h1h3 control (current controller outputs)

h1h3h5 control (about 3A less). For the tested point $(5.5 \mathrm{Nm}$ and 570rpm), the power factors take the acceptable value of $0.90,0.82,0.86$ and 0.87 for h1, h3, h1h3 and h1h3h5 controls respectively.
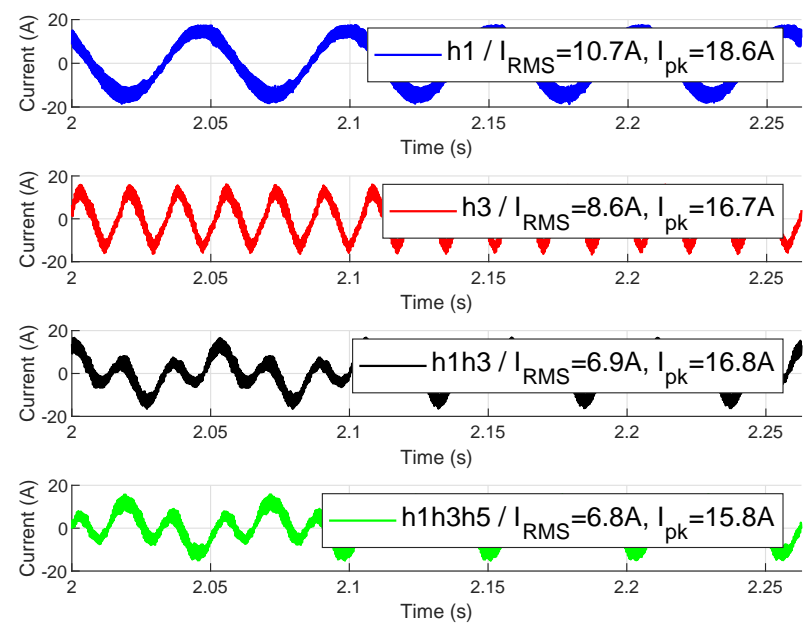

Fig. 14. Experimental phase A currents for the four controls (with $5.5 \mathrm{Nm}$ average torque)

In order to evaluate the TRL for $h 1, h 3, h 1 h 3$ and $h 1 h 3 h 5$ controls, a high number of torque waveforms has been recorded: Table III gives for each control the average, maximum, minimun TRL and the standard deviation. Fig. 15 reports a typical sample of the electromagnetic torques obtained with the four possible MTPA controls. The lowest TRL is obtained with h1 control (about 6\%) while h1h3 also provides a quite low TRL (about 9\%). The TRL are slightly increased with h1h3h5 and h3 controls (about $10 \%$ and $11 \%$ respectively). As the experimental back-emf (see Fig.11) reveals quite sinus waveforms for $h 1$ and $h 3$ virtual machines, $h 1$ and $h 3$ controls should result in quite similar TRL. This property is discussed in part II-B: due to the electrical harmonic distribution, sinus virtual machines will provide constant torque with multimachine control. The observed difference (about $6 \%$ with h1 versus about $11 \%$ with $\mathrm{h} 3$ ) could be explained by the fact that third harmonic current injection is more demanding for the controller. Anyway, for the four controls and especially for the rated $\mathrm{h} 1 \mathrm{~h} 3 \mathrm{control}$, the TRL is low. In particular, the reduction of the TRL with h1h3 control (about 9\%) referring to h3 control (about 11\%) illustrates the machine design adaptation to the bi-harmonic control (since, usually, higher the number of injected current harmonics is, higher the torque ripple is [21]).

TABLE III

SUMMARY OF THE TRL MEASUREMENTS

\begin{tabular}{ccccc} 
Control & $\mathrm{h} 1$ & $\mathrm{~h} 3$ & $\mathrm{~h} 1 \mathrm{~h} 3$ & $\mathrm{~h} 1 \mathrm{~h} 3 \mathrm{~h} 5$ \\
\hline Average TRL (\%) & 6.2 & 11.3 & 9.3 & 10.2 \\
Maximum TRL (\%) & 7.3 & 12.9 & 10.3 & 10.9 \\
Minimum TRL (\%) & 5.3 & 9.9 & 8.5 & 9.4 \\
Standard deviation (\%) & 0.6 & 1.0 & 0.5 & 0.4
\end{tabular}
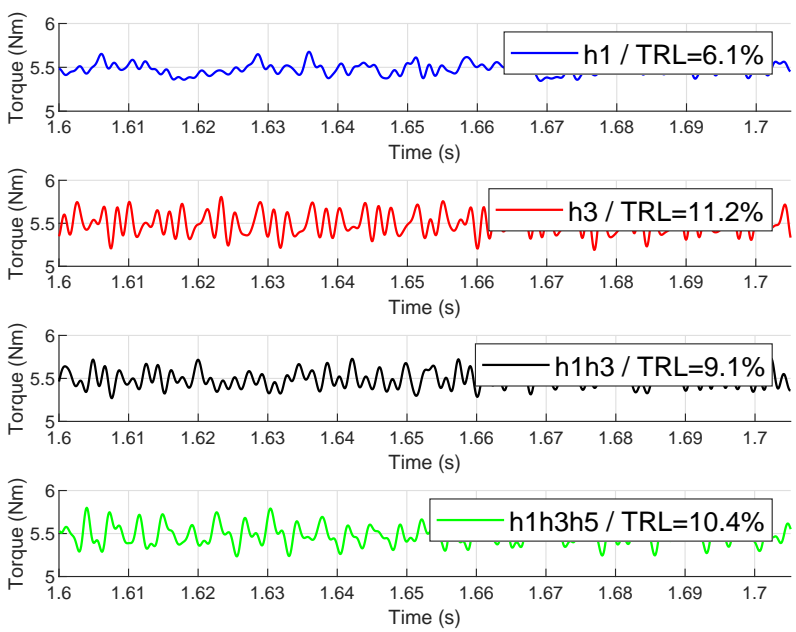

Fig. 15. Experimental electromagnetic torques for h1, h3, h1h3 and h1h3h5 controls

Finally, these tests confirm that h1h3 or h1h3h5 controls are the right controls for the bi-harmonic 7-phase machine. A low TRL is obtained and the efficiency better than with h1 or h3 controls. The Concordia transform ensures an effective decoupling control between the first, third and fifth current harmonics.

\section{CONClusion}

As multi-phase machines with tooth-concentrated windings and $s_{p p}=0.5$ offer interesting characteristics (simplified manufacturing, no space subharmonic, fault-tolerant ability), the paper shows that a bi-harmonic (electromotive force with third-harmonic amplitude equal to $160 \%$ of the fundamental) seven-phase drive can be a solution to achieve high torque quality (low ripples) even with simultaneaous optimal injections of two harmonics (according to MTPA supply). Regarding the design of the SPM rotor, an appropriate (and easy to make) segmentation of the magnet layer into two identical radially magnetized tiles is proposed. Experimental results confirm the ability of the machine to provide smooth torque even with strong distortion in current. Further studies 
are in progress to operate the machine in faulty modes and in flux weakening modes.

\section{REFERENCES}

[1] E. Levi, "Multiphase electric machines for variable-speed applications," Industrial Electronics, IEEE Transactions on, vol. 55, no. 5, pp. 1893 1909, 2008.

[2] E. Semail, X. Kestelyn, and A. Bouscayrol, "Right harmonic spectrum for the back-electromotive force of an n-phase synchronous motor," in Industry Applications Conference, 2004. 39th IAS Annual Meeting. Conference Record of the 2004 IEEE, vol. 1, Oct 2004, p. 78.

[3] K. Wang, Z. Zhu, and G. Ombach, "Torque improvement of fivephase surface-mounted permanent magnet machine using third-order harmonic," Energy Conversion, IEEE Transactions on, vol. 29, no. 3 , pp. 735-747, Sept 2014.

[4] Z. Q. Zhu and D. Howe, "Influence of design parameters on cogging torque in permanent magnet machines," IEEE Transactions on Energy Conversion, vol. 15, no. 4, pp. 407-412, December 2000.

[5] A. M. EL-Refaie, "Fractional-slot concentrated-windings synchronous permanent magnet machines: Opportunities and challenges," IEEE Transactions on Industrial Electronics, vol. 57, no. 1, pp. 107-121, Jan 2010.

[6] B. Aslan, E. Semail, and J. Legranger, "General analytical model of magnet average eddy-current volume losses for comparison of multiphase pm machines with concentrated winding," Energy Conversion, IEEE Transactions on, vol. 29, no. 1, pp. 72-83, March 2014.

[7] B. Mecrow, A. Jack, J. Haylock, and J. Coles, "Fault tolerant permanent magnet machine drives," IEE-Proc.Electr. Power Applications, vol. 143, no. 6, pp. 437-442, 1996.

[8] H. Zahr, F. Scuiller, and E. Semail, "Five-phase spm machine with electronic pole changing effect for marine propulsion," in ESARS ITEC 4th International Conference on Electrical Systems for Aircraft, Railway, Ship propulsion and Road Vehicles and International Transportation Electrification Conference, Nov 2016.

[9] F. Scuiller, H. Zahr, and E. Semail, "A bi-harmonic five-phase spm machine with low ripple torque for marine propulsion," in 2017 IEEE International Electric Machines and Drives Conference (IEMDC), May 2017, pp. 1-7.

[10] H. Zahr, J. Gong, E. Semail, and F. Scuiller, "Comparison of optimized control strategies of a high-speed traction machine with five phases and bi-harmonic electromotive force," Energies, vol. 9, no. 12, 2016. [Online]. Available: https://www.mdpi.com/1996-1073/9/12/952

[11] J. Gong, H. Zahr, E. Semail, M. Trabelsi, B. Aslan, and F. Scuiller, "Design considerations of five-phase machine with double $\mathrm{p} / 3$ p polarity," IEEE Transactions on Energy Conversion, vol. 34, no. 1, pp. 12-24, March 2019

[12] F. Scuiller, "Design of a 7-phase surface-mounted pm machine with tooth-concentrated winding," in 2018 XIII International Conference on Electrical Machines (ICEM), Sep. 2018, pp. 2458-2464.

[13] J. Figueroa, J. Cros, and P. Viarouge, "Generalized transformations for polyphase phase-modulation motors," IEEE Transactions on Energy Conversion, vol. 21, no. 2, pp. 332-341, June 2006.

[14] E. Semail, X. Kestelyn, and F. Locment, "Fault tolerant multiphase electrical drives: the impact of design," Eur. Phys. J. Appl. Phys., vol. epjap:2008057, 2008.

[15] D. Casadei, M. Mengoni, G. Serra, A. Tani, L. Zarri, and L. Parsa, "Control of a high torque density seven-phase induction motor with field-weakening capability," in Industrial Electronics (ISIE), 2010 IEEE International Symposium on, July 2010, pp. 2147-2152.

[16] F. Locment, E. Semail, and X. Kestelyn, "Vectorial approach-based control of a seven-phase axial flux machine designed for fault operation," IEEE Transactions on Industrial Electronics, vol. 55, no. 10, pp. 36823691, Oct 2008.

[17] E. Semail, A. Bouscayrol, and J.-P. Hautier, "Vectorial formalism for analysis and design of polyphase synchronous machines," Eur. Phys. J., vol. AP 22, pp. 207-220, 2003.

[18] F. Scuiller, E. Semail, J.-F. Charpentier, and P. Letellier, "Multi-criteria based design approach of multiphase permanent magnet low speed synchronous machines," IET Electric Power Applications, vol. 3, no. 2, pp. 102-110, 2009.

[19] S. Williamson and S. Smith, "Pulsating torque and losses in multiphase induction machines," IEEE Transactions on Industry Applications, vol. 39, no. 4, pp. 986-993, July/August 2003.
[20] X. Kestelyn and E. Semail, "A vectorial approach for generation of optimal current references for multiphase permanent-magnet synchronous machines in real time," Industrial Electronics, IEEE Transactions on, vol. 58, no. 11, pp. $5057-5065$, nov. 2011.

[21] F. Scuiller, "Magnet shape optimization to reduce pulsating torque for a five-phase permanent-magnet low-speed machine," Magnetics, IEEE Transactions on, vol. 50, no. 4, pp. 1-9, April 2014.

[22] R. Lateb, N. Takorabet, and F. Meibody-Tabar, "Effect of magnet segmentation on the cogging torque in surface-mounted permanentmagnet motors," IEEE Transactions on Magnetics, vol. 42, no. 3, pp. 442-445, March 2006.

[23] A. B. Proca, A. Keyhani, A. El-Antably, W. Lu, and M. Dai, "Analytical model for permanent magnets motors with surface mounted magnets," IEEE Transactions on Energy Conversion, vol. 18, no. 3, pp. 386-391, September 2003.

[24] D. Meeker, "Finite element method magnetics, version 4.2, users manual," FEMM official website, October 2010.

[25] R. Siebert, J. Schneider, and E. Beyer, "Laser cutting and mechanical cutting of electrical steels and its effect on the magnetic properties," IEEE Transactions on Magnetics, vol. 50, no. 4, pp. 1-4, April 2014.

\section{BIOGRAPHIES}

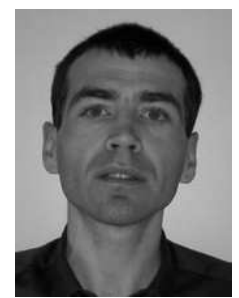

Franck Scuiller (M'11) received the Electrical Engineering degree (M.Sc. degree) from ENSIEG, INPG, France (Grenoble National Polytechnic Institute) in 2001 and the Ph.D. degree from Arts et Métiers ParisTech in 2006. In 2007, he was a lecturer in French Naval Academy. From 2008 to 2011, he was a technical project manager in warship electric power systems for DCNS company (Lorient, France). Since September 2011, he is an Associate Professor in Electrical Engineering in the French Naval Academy. His research interest is multi-phase machines for marine applications (ship propulsion, marine current turbine).

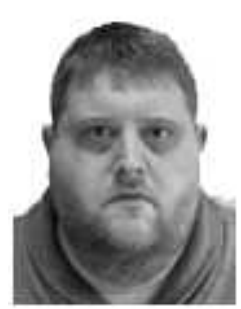

Florent Becker was born in France, in 1987. He received the M.S degree from Université de Nancy and $\mathrm{Ph}$.D. Degree in Electrical Engineering from Université de Lorraine, IJL/GREEN, France in 2011 and 2017 respectively. Since 2017 he is with the French Naval Academy in Brest, France. His research interests are fault tolerant power systems, multi-Level converter, multi-phase machine, renewable energy and High Voltage Direct Current (HVDC).

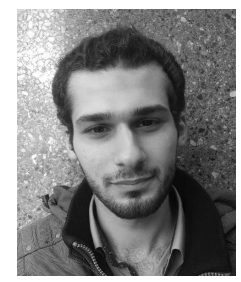

Hussein Zahr (SM'13) received the B.S. and M.S. degrees from the Faculty of engineering, Lebanese university and Ecole Polytechnique de Nantes, University de Nantes, and the Ph.D. degree from the Ecole Nationale Supérieure des Arts et Metiers in 2016. He is currently postdoctoral researcher in electrical engineering at Ecole Nationale Supérieure des Arts et Metiers(ENSAM), Laboratory of Electrical Engineering and Power Electronics of Lille (L2EP). 


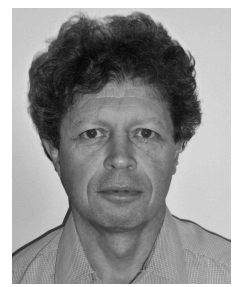

Eric Semail (M'02) graduated from the Ecole Normale Supérieure, Paris, France, in 1986, and received the Ph.D. degree with a thesis entitled Tools and studying method of polyphase electrical systems. Generalization of the space vector theory from the University of Lille, France, in 2000. He became an Associate Professor at the Engineering School of Arts et Métiers ParisTech, Lille, France, in 2001 and a Full Professor in 2010. In the Laboratory of Electrical Engineering of Lille (L2EP), France, his fields of interest include design, modeling, and control of multiphase electrical drives (converters and ac drives). More generally, he studies, as a Member of the Control team of L2EP, multimachine and multiconverter systems. Fault tolerance for electromechanical conversion at variable speeds is one of the applications of the research with industrial partners in fields such as automotive, marine, and aerospace. Since 2000, he has collaborated on the publication of 33 scientific journals, 64 International Congresses, 5 patents, and 2 chapters in books at Wiley editions. 